\title{
Premature ejaculation: Pharmacotherapy vs group psychotherapy alone or in combination
}

\author{
Carlo Pavone, Daniela Abbadessa, Giuseppa Gambino, Giovanna Scaduto, Marco Vella \\ Section of Urology, Department of Surgical, Oncological and Stomatological Sciences, University of Palermo, Palermo, Italy.
}

\begin{abstract}
Summary Objectives: Premature Ejaculation (PE), the commonest sexual dysfunction in males, is generally treated with local anesthetic and SSRI (Dapoxetine). The aim of our study was investigate Group Psychotherapy as an alternative treatment for PE and compare the efficacy of pharmacological treatment and psychotherapy, either alone or in combination, in terms of response and improved Quality of Life (QoL). From a male outpatient population screened for PE, those who received a diagnosis of $P E$ were proposed for the study, enrolled and divided into 3 groups (A, B and C). Each group was treated with Dapoxetine, Group Psychotherapy alone and Dapoxetine and Group Psychotherapy, respectively. Materials and methods: Out of 1237 male outpatients, 353 received a diagnosis of Premature Ejaculation. Of them, 279 were enrolled in the study and randomized into 3 groups (A, B and C). Only 157 patients were evaluable. Before and after treatments all participants completed two questionnaires to evaluate PE status and anxiety and referred their IELT. Results: GROUP A: The mean post-treatment Premature Ejaculation Diagnostic Tool (PEDT) score decreased from 12.95 to 8.26, while the mean Intra-vaginal Ejaculation Latency Time (IELT) increased from $50.77 \mathrm{sec}$ to $203 \mathrm{sec}$. ( $p<0.05)$; GROUP B: Reduction in the mean PEDT from 13.44 to 5.11 and an increased IELT from 48.33 to $431.11 \mathrm{sec}$ ( $p<0.001)$; GROUP C: The mean post-treatment PEDT score decreased from 12.29 to 5.57, while the mean IELT increased from 46.86 to $412.14 \mathrm{sec}(p<0.001)$. All groups recorded an improvement in anxiety.

Conclusions: According to our results Group Psychotherapy is an alternative method of treatment for PE. Group

Psychotherapy plays a significant role in the treatment of PE, determining a better improvement of symptoms than Dapoxetine alone even if not statistically significant.
\end{abstract}

KEY WORDS: Premature ejaculation; Group psychotherapy; Psychotherapy; Dapoxetine; Sexual therapy.

Submitted 11 October 2016; Accepted 1 March 2017

\section{INTRODUCTION}

According to an updated report from the International Society of Sexual Medicine (ISSM), Premature Ejaculation (PE) is defined as a male sexual dysfunction characterized by ejaculation that always or nearly always occurs prior to or within about 1 minute of vaginal penetration from the first sexual experience (lifelong type) or a clinically significant reduction in latency time often to about 3 minutes or less (acquired type), the inability to delay ejaculation on all or nearly all vaginal penetrations, and negative person- al consequences ( 1 ). It seems to be the most common sexual disorder in males (2) with an incidence of about 25$40 \%$ of the world's male population. It's etiology is multifactorial and include biological, psychological, social and situational factors. All psychological and behavioral approaches to the treatment of PE were based on the hypothesis of an emotional origin of the disorder, and on physical rehabilitation through special techniques such as squeeze-pause and start-stop (3), but pharmacotherapy with serotonin selective re-uptake inhibitors (SSRIs) has changed the management of this disorder and eclipsed the use of psychological treatments (4). Nowadays, the literature seems to identify both organic and psychological multifactorial events in the pathogenesis of PE that are involved to varying extents in each patient. A multifactorial pathogenesis calls for a multidisciplinary approach that strives to achieve a global evaluation of the patient.

Several studies have concluded that combined therapy is more effective than pharmacological therapy alone for men with Erectile Dysfunction (ED) and PE (5, 6). Although psychotherapy has been used and considered as a possible treatment of $\mathrm{PE}$, the use of group psychotherapy that had a huge emphasis during the 1970 s and 1980s $(7,8)$ within psychiatry and psychology nowadays has fallen into disuse in the clinical practice and has been considered not fit for sexual disorder by some authors (9). As far as we know there are no studies comparing group psychotherapy with pharmacotherapy. Our prospective and randomized study has the intent to evaluate the feasibility of Group Psychotherapy in treatment of PE and evaluate the efficacy of two different treatments (pharmacological and psychological), either alone or in combination and as far as we know it's the first study comparing the pharmacotherapy to a grouppsychotherapy.

\section{MATERIALS AND METHODS}

Between January and December 2012, a sample of male outpatients aged 20 to 68 years was screened for PE. The $\mathrm{PE}$ patients were enrolled in the study.

Inclusion criteria were: Lifelong PE measured with Intravaginal Ejaculatory Latency Time (IELT) $\leq 2$ minutes and Premature Ejaculation Diagnostic Tool (PEDT) $>9$ (see below).

Exclusion criteria were: presence of psychiatric disor- 
ders requiring medical treatment, drugs and alcohol abuse, severe chronic disease, neoplastic diseases.

This study was performed at the Urology Department, University of Palermo, outpatients clinic.

Patients, after giving informed consent to participation in the study, were randomly assigned following simple randomization procedures (computerized random numbers) to 3 different treatment groups as follows:

Group Treatment A: Dapoxetine

Group Treatment B: Group Psychotherapy alone.

Group Treatment C: Dapoxetine (as in group A) in combination with Group Psychotherapy.

Patients of all the 3 groups were also followed up by the urologist for 12 weeks during the study with 4 monthly scheduled visits. IELT was collected as reported by patients at the beginning and at the end of the study.

Prior to treatment any participant, regardless of treatment group, completed two validated questionnaires, and repeated them at the end of all treatments. Differences between scores at baseline and after treatments were evaluated.

The PEDT was used to assess PE status. This five-item questionnaire was developed according to the DSM-IVTR criteria used to diagnose PE (10), and covers the following five domains: ejaculation control, frequency of PE, ejaculation with minimal sexual stimulation, distress, and interpersonal difficulty. Response options for all items are on a five-point Likert-type scale ranging from 0 to 4 , with higher scores indicating greater sexual impairment. The total score is computed by summing up all item scores.

Therefore, the primary endpoint of the study was to evaluate differences in PEDT scores across groups, before and after treatment. Secondary endpoint was IELT defined as the mean duration of intercourse, expressed in seconds. IELT was reported from patients in order to reduce the anxiety induced by the use of a device such as a chronometer: this anxiety could negatively impact on the PE, reducing IELT (11); moreover, as reported by Jannini et al. (11) "the presence of a stopwatch, even for short diagnostic purpose, is not frequently accepted". At ante-portam ejaculation was assigned an IELT of 0 minutes.

In order to identify anxiety in the psychological context of the examined subjects, the State-Trait Anxiety Inventory (STAI) test, a self-administered questionnaire, was used $(12,13)$. It consists of two different scales (STAI-X1 and STAI-X2) of 20 items each, with multiple choice answers (never, sometimes, often, and always). STAI-X1 is directed at investigating the state anxiety and provides a transitory estimation of the emotional state, which varies in intensity and fluctuates in time as a function of the stressors impinging on the individual at the time of starting the procedure. STAI-X2 is directed at relatively stable individual differences in subjects who become anxious in different circumstances (14) Psychometric tests were performed to identify the presence of state anxiety (STAI-Xl) and trait anxiety (STAI$\mathrm{X} 2$ ) before and after each treatment, as well as the prepost treatment anxiety fluctuations. The threshold scores for STAI questionnaires were chosen according to previously published methods (15) (normal range $=28-44$ and 28-48 for the X1 and X2 form, respectively).
All Groups Psychotherapy were conducted by an expert postdoctoral-level psychotherapists trained in GroupAnalytical approach: Group Psychotherapy was preceded by 2 individual interviews aimed at discussing and informing upon general aspects of Group Psychotherapy and its rules.

Group Psychotherapy was delivered in 16 weekly sessions of 2 hours each. Time was spent at the end of each session to help participants to integrate cognitively the experience with theory. Each group, open and shortterm, was composed of about 10 male patients, and after randomization resulted homogeneous for IELT $(\leq 2)$, PEDT $(\geq 9)$ and STAI-Y $(\geq 40)$.

In our study we used the Homogeneous Group Psychotherapy, time-limited, that is characterized by the presence of patients who shared the same symptom, diagnosis or typology of problems (i.e. PE). The earliest experience of this Group Psychotherapy is due to Pratt $(16,17)$, Professor of Medicine at Boston Hospital, who developed a class-based method for treating patients with psychosomatic conditions and emotional dimensions of chronic and recurrent illness, and traced some dynamics which could be activated in this type of group. The presence of patients with similar issues offers participants the opportunity to interact with others in a safe, supportive environment: this fact facilitates the expression of those feelings which are often difficult to express outside of group, and to try out new behaviors and engage with others not only in receiving valuable feedback from other group members, but also in giving it. In fact homogeneity is at the basis of the mirroring process that enables the emergence of commuting, resonance and effective narration functions that, at the same time, generate a special sense of belonging (18).

The goals of Group Psychotherapy was to elaborate the meaning of sexual dysfunction, to permit patients to acquire internal and relational competence useful to achieve a most satisfying quality of life, to increase the ability to analyze and manage new events, start thinking to possible changes and ameliorations after a treatment cycle, reduction of anxiety, increase of compliance to medical treatment.

In this study we used Dapoxetine $30 \mathrm{mg}$ (dose increasable to $60 \mathrm{mg}$ if ineffective), 1 tablet 1 hour before intercourse with a couple of glasses of water.

An alpha level of .05 (two-tailed) was chosen for all statistical tests in this study. We tested for differences between treatment groups on IELT and PEDT, STAI-X1 and STAI-X2 by using analyses of variance, before and at the end of treatment; post-hoc Tukey HSD tests were performed to investigate differences across groups at the end of treatment; finally, to determine the effects of the treatments in producing clinical improvement at the end of treatment, paired samples t-tests were performed. Statistical analysis was performed using the computer statistical package SPSS/17.0 (SPSS, Chicago, IL, USA).

To determine the effects of the treatments in producing clinical reduction of state and trait anxiety at the end of treatment, we performed an intention to treat Cochran's $\mathrm{Q}$ test of the percentage of patients who had reduced anxiety at STAI-X1 and/or STAI-X2. For each measure, two categories were created: normal range and patholog- 
ical range. Patients were deemed to have clinically reduced anxiety if their score was shifted from the pathological range to the normal range; otherwise, those not having reduced anxiety remained in the normal range or in the pathological range. An Intention to Treat Cochran's Q test (ITT) was performed on a larger data set comprising subjects who completed the study, as well as subjects who dropped out the study for various causes, so not being analyzed in the post-test phase. In such an analysis the pre-test condition (normal vs pathological) was carried forward to serve as the post-test condition of dropouts. No patient witnessed either an increased in their state or trait anxiety level. Effect sizes were finally calculated: Cohen's d was calculated for t tests, Cohen's $f$ for ANOVAs; Phi coefficient for the $X^{2}$ tests, and Cramer's V for the Cochran's Q tests.

\section{RESULTS}

Figure 1 shows a flow chart of the study. Out of 1237 male outpatients, 353 received a diagnosis of $\mathrm{PE}$ and a total sample of 279 patients who met the entry criteria, agreed to randomization and was analyzed in a pre-treatment phase. Patients were randomly divided in 3 groups, each of them was composed of 93 patients. Out of 279 enrolled patients, only 157 patients completed the intervention and were analyzed post-treatment; in detail the drop out rate was of 33\% in Group A, 36\% in group B and $61 \%$ in Group C respectively (drop out reasons are showed in Figure 1). There were no significant differences in all demographic and clinical variables between eligible patients carried through the intervention to the end and those who left the study. Preliminary comparisons at baseline demonstrated that the three treatment groups did not show significant differences on 15 demographic and clinical variables (age, marital status, employment status, stable love affair, cigarette smoking, diabetes, hypertension, obesity, heart condition, neuropathy, prostatitis, sexually transmitted diseases, depression, anxiety, and erectile dysfunction). The demographic and clinical characteristics of the treatment groups at baseline are shown in Table 1.

Then, it was verified that assumptions for ANOVAs, paired samples t-tests and Cochran's Q tests were not violated. Table 2 shows the results at baseline and at the end of treatment for all patients for whom results were available on the four main outcome

\section{Figure 1.}

measures (IELT, PEDT, STAI-X1 and STAY-X2). At baseline, no differences in outcome measures were found between the groups (see Table 2). All three groups improved during treatment, while at the end of treatment groups $B$ and $C$ improved more significantly than group A, on all the study variables. No significant differences among group B and group $C$ were found at the end of treatment, on any of the study variables (Table 2).

Finally, Table 3 shows the number (and percentage) of patients who were in the normal or pathological range of anxiety in each group at baseline and at the end of treatment. In the sample as a whole, patients significantly reduced their level of both state and trait anxiety (STAI$\mathrm{X} 1$ and STAI-X2, respectively) from the pathological to the normal range. Specifically, both state and trait anxiety significantly decreased in all groups, and most patients improved to the normal range (Table 3 ).

\section{Discussion}

PE seems to be the most common sexual disorder in males (2). As described previously PE has a multifactorial etiology and many authors concentrated their attention on the study of a biopsychosocial approach to this disorder $(19,29,30)$. Psychological and behavioral approaches to the treatment of PE were based on the hypothesis of an emotional origin of the disorder, and on physical rehabilitation through special techniques such as squeeze-pause and start-stop (3). Nowadays the liter-

Flow diagram of the progress through the phases of the randomized study.

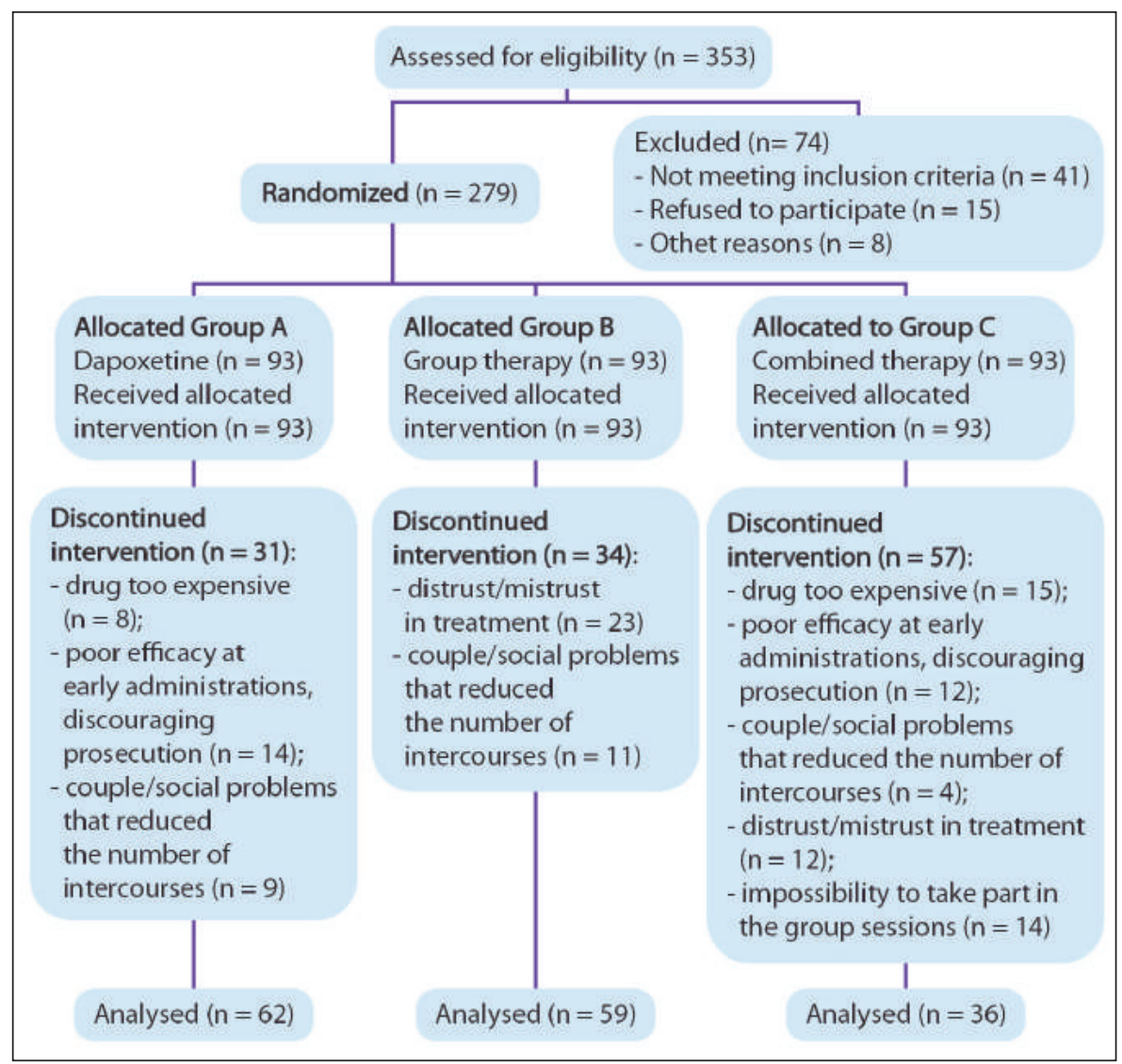


Table 1.

Demographic and clinical features of treatment groups at baseline.

Figures are numbers (percentage) of patients unless stated otherwise.

\begin{tabular}{|l|c|c|c|c|c|}
\hline $\begin{array}{l}\text { Patient } \\
\text { characteristics }\end{array}$ & $\begin{array}{c}\text { Group A } \\
\text { Dapoxetine }(\mathbf{n}=\mathbf{9 3})\end{array}$ & $\begin{array}{c}\text { Group B } \\
\text { Group therapy } \mathbf{n}=\mathbf{9 3})\end{array}$ & $\begin{array}{c}\text { Group C } \\
\text { Combination }(\mathbf{n}=93)\end{array}$ & $\begin{array}{c}\text { Total sample } \\
(\mathbf{n}=\mathbf{2 7 9})\end{array}$ & $\begin{array}{c}\text { Differences } \\
\text { between groups }\end{array}$ \\
\hline Mean (range) age (years) & $45.79(22-64)$ & $37.00(28-56)$ & $48.44(20-68)$ & $45.32(20-68)$ & $F(2,276)=2.12, n s$ \\
\hline Marital status - Married & $39(41.93)$ & $48(51.61)$ & $36(38.71)$ & $123(44.09)$ & $X^{2}(2)=3.40, n s$ \\
\hline Marital status - Single & $47(50.54)$ & $34(36.56)$ & $48(51.61)$ & $129(46.24)$ & $X^{2}(2)=5.28, n s$ \\
\hline Marital status - Divorced & $7(7.53)$ & $11(11.83)$ & $9(9.68)$ & $27(.10)$ & $X^{2}(2)=.98, n s$ \\
\hline Employment status - Employee & $30(32.26)$ & $23(24.73)$ & $37(39.78)$ & $90(32.26)$ & $X^{2}(2)=4.82, n s$ \\
\hline Employment status - Director & $7(7.53)$ & $5(5.38)$ & $4(4.30)$ & $16(5.73)$ & $X^{2}(2)=.93, n s$ \\
\hline Employment status - Self-employed & $11(11.82)$ & $13(13.98)$ & $6(6.45)$ & $30(10.75)$ & $X^{2}(2)=2.91, n s$ \\
\hline Employment status - Unemployed & $45(48.38)$ & $52(55.91)$ & $46(49.46)$ & $133(51.25)$ & $X^{2}(2)=1.23, n s$ \\
\hline Stable love affair & $69(74.19)$ & $77(82.80)$ & $79(84.95)$ & $225(80.65)$ & $X^{2}(2)=3.86, n s$ \\
\hline Cigarette smoking & $31(33.33)$ & $27(29.03)$ & $19(20.43)$ & $77(27.60)$ & $X^{2}(2)=4.02, n s$ \\
\hline Diabetes & $7(7.53)$ & $3(3.23)$ & $8(8.60)$ & $18(6.45)$ & $X^{2}(2)=2.48, n s$ \\
\hline Hypertension & $15(16.13)$ & $17(18.28)$ & $24(25.81)$ & $56(20.07)$ & $X^{2}(2)=2.99, n s$ \\
\hline Dbesity & $3(3.23)$ & $5(5.38)$ & $10(10.75)$ & $18(6.45)$ & $X^{2}(2)=4.63, n s$ \\
\hline Heart condition & $6(6.45)$ & $13(13.98)$ & $10(10.75)$ & $29(10.39)$ & $X^{2}(2)=2.85, n s$ \\
\hline Neuropathy & $1(1.08)$ & $2(2.15)$ & $1(1.08)$ & $4(1.43)$ & $X^{2}(2)=.51, n s$ \\
\hline Prostatitis & $3(3.23)$ & $4(4.30)$ & $8(8.60)$ & $15(5.38)$ & $X^{2}(2)=2.96, n s$ \\
\hline Sexually transmitted diseases & $0(0)$ & $0(0)$ & $0(0)$ & $0(0)$ & \\
\hline Depression & $33.23)$ & $6(6.45)$ & $2(2.15)$ & $11(3.94)$ & $X^{2}(2)=2.46, n s$ \\
\hline Anxiety & $18(19.35)$ & $26(27.96)$ & $31(33.33)$ & $75(26.88)$ & $X^{2}(2)=4.70, n s$ \\
\hline Erectile dysfunction & $46(49.46)$ & $38(40.86)$ & $41(44.09)$ & $125(44.80)$ & $X^{2}(2)=1.42, n s$ \\
\hline
\end{tabular}

ature seems to identify both organic and psychological multifactorial events in the pathogenesis of $\mathrm{PE}$ that are involved to varying extents in each patient. With the introduction of SSRI in the treatment of PE several studies have concluded that combined therapy is more effective than pharmacological therapy alone for men with ED and PE $(5,6)$. As discussed before, the use of group psychotherapy that had a huge emphasis during the 1970s and 1980s $(7,8)$ within psychiatry and psychology, nowadays has fallen into disuse in the clinical practice and has been considered not fit for sexual disorder by some authors (9). Those who are affected by PE often appear to be discouraged by the unsatisfying duration of intercourse, as well as by the sense of inadequacy related to their inability to satisfy their partner, it has negative consequences on the Quality of Life (QoL) of patients and their partners. A recent study conducted by Limoncin et al. (22) showed that women with a partner affected by PE were more likely than controls to experience significant sexual distress.

Until 2008 the pharmacological treatment of PE was based on off-label use of SSRIs; in 2009 the European Agency for the Evaluation of Medicinal Products (EMA) approved the use of Dapoxetine for the specific treatment of PE in patients aged between 18 and 64 years. The efficacy of Dapoxetine compared to placebo has been proven in many studies. Although its side effects are rarely serious and generally well tolerated (23), patients' compliance to

Table 2.

Mean scores on two main outcome scales at baseline and at the end of treatment.

\begin{tabular}{|c|c|c|c|c|c|}
\hline Outcome measures & $\begin{array}{l}\text { Mean scores } \\
\text { (SD; } 95 \% \text { Cl) (n) }\end{array}$ & $\begin{array}{c}\text { Differences } \\
\text { between groups }\end{array}$ & \multicolumn{2}{|c|}{ Tukey HSD Post-hoc tests } & \\
\hline Patient characteristics & Group A - Dapoxetine & Group B - Group therapy & Group C - Combination & & \\
\hline \multicolumn{6}{|l|}{ IELT: } \\
\hline Baseline (279) & $\begin{array}{c}50.77(13.52 ; 48.02 \\
\text { to } 53.52)(n=93) \\
\end{array}$ & $\begin{array}{c}46.86(10.95 ; 48.54 \\
\text { to } 53.00)(n=93)\end{array}$ & $\begin{array}{l}48.33(13.11 ; 45.67 \\
\text { to } 50.99)(n=93) \\
\end{array}$ & $F(2,276)=2.29, n s$ & $\begin{array}{c}\text { For all pairwise comparisons: } \\
p s>.05\end{array}$ \\
\hline \multirow[t]{2}{*}{ End of treatment (139) } & $\begin{array}{l}231.86(39.97 ; 221.91 \\
\text { to } 241.81)(n=62)\end{array}$ & $\begin{array}{c}412.14(45.36 ; 400.57 \\
\text { to } 423.71)(n=59)\end{array}$ & $\begin{array}{l}431.11(53.96 ; 413.48 \\
\text { to } 448.74)(n=36)\end{array}$ & $\begin{array}{c}F(2,154)=320.50 \\
p<.001\end{array}$ & $\begin{array}{c}\text { Group A vs Group B: } p<.001 ; \\
\text { Group A vs Group C: } p<.001 ; \\
\text { Group B vs Group C: } n s\end{array}$ \\
\hline & $t(61)=-35.67, p<.001$ & $t(58)=-61.86, p<.001$ & $t(56)=-42.56, p<.001$ & & \\
\hline \multicolumn{6}{|l|}{ PEDT: } \\
\hline Baseline (279) & $\begin{array}{l}12.95(2.32 ; 12.48 \\
\text { to } 13.42)(n=93)\end{array}$ & $\begin{array}{r}12.29(1.97 ; 11.89 \\
\text { to } 12.69)(n=93)\end{array}$ & $\begin{array}{l}13.44(6.28 ; 12.16 \\
\text { to } 14.72)(n=93)\end{array}$ & $F(2,276)=1.91, n s$ & $\begin{array}{l}\text { For all pairwise comparisons: } \\
\qquad s>.05\end{array}$ \\
\hline \multirow[t]{2}{*}{ End of treatment (139) } & $\begin{array}{l}10.61(8.59 ; 8.47 \\
\text { to } 12.75)(n=62)\end{array}$ & $\begin{array}{l}5.57(10.62 ; 2.86 \\
\text { to } 8.28)(n=59)\end{array}$ & $\begin{array}{l}5.11(13.86 ; .58 \\
\text { to } 9.64)(n=36)\end{array}$ & $\begin{array}{l}F(2,154)=7.57 \\
p<.05\end{array}$ & $\begin{array}{l}\text { Group A vs Group B: } p<.05 ; \\
\text { Group A vs Group C: } p<.05 ; \\
\text { Group B vs Group C: } n s\end{array}$ \\
\hline & $t(61)=2.14, p<.05$ & $t(58)=4.86, p<.001$ & $t(35)=3.61, p<.001$ & & \\
\hline
\end{tabular}


Table 3.

Number (\%) of patients' range at STAI-X1 and STAI-X2, at baseline and at the end of treatment.

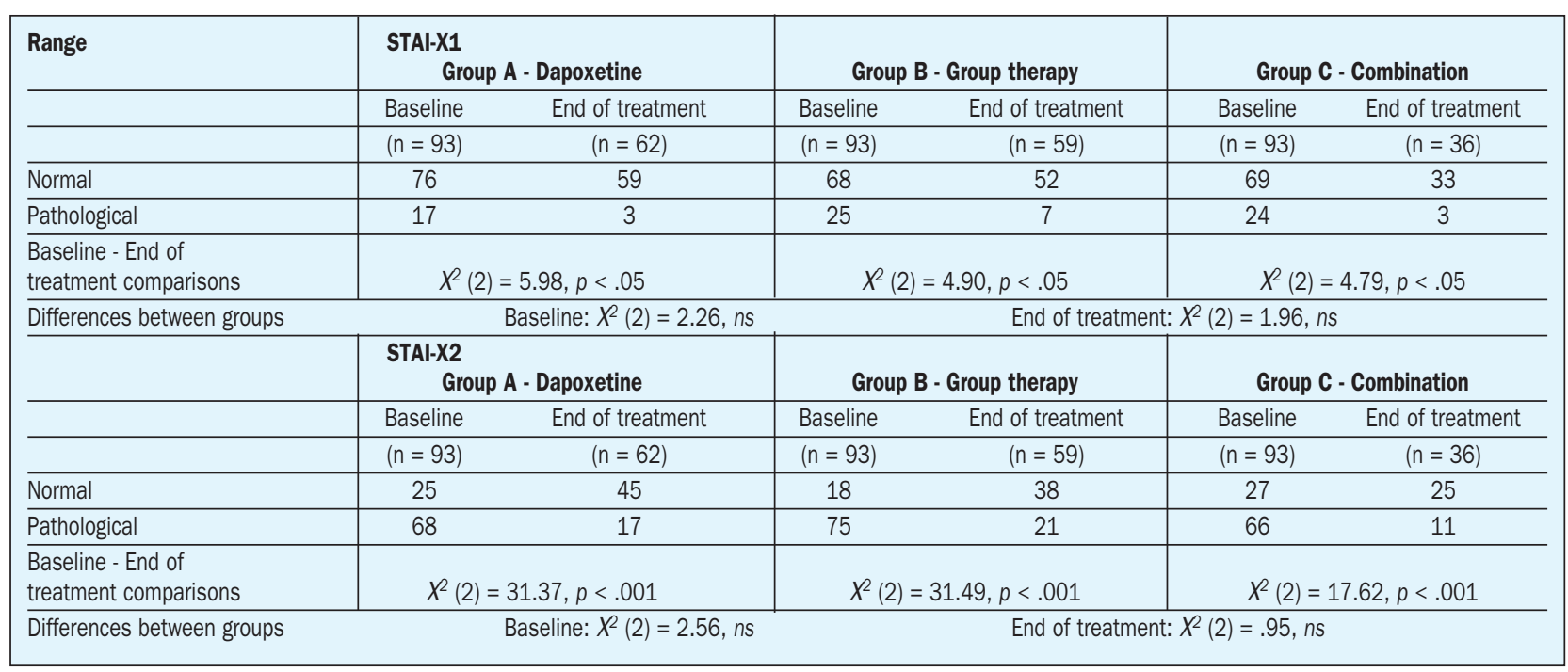

Dapoxetine still remain poor as demonstrated in recent study in which the dropout at one year was of about 90\% (24). Some authors believe that the first approach with PE must consider topical therapy with anesthetic gel (lidocain, prilocain), which has demonstrated greater efficacy compared to placebo (25). Some Authors expressed concern that the administration of medical treatments for sexual disorders without attention to psychological factors may not be sufficient $(26,27)$.

According to Hunt and McHale (28) men suffering from andrological problems, such as ED and PE, commonly have concomitant psychosocial problems, vary in nature and severity, and that in many cases they may benefit from some form of psychotherapy.

Group therapy is a form of psychotherapy in small group of individuals with the purpose to assist them in emotional growth and personal problem solving, that encompasses many different kinds of groups with varying theoretical approaches. Group psychotherapy characterized by a psychodynamic approach (such as in our study) is able to facilitate active and introspective work among the participants with the aim to reduce invalidating symptoms and to achieve a change in their personality and modality of interaction.

Moreover, our choice of a short group psychotherapy was born from the evidence of effectiveness in patients affected by moderate anxiety and depression (29); furthermore, short psychotherapy showed lower drop-out rate compared to long term one (30). On the contrary, in our study patients' partners were not included to reduce/minimize patients' inhibition and create an environment free from couple dynamics (feelings like sadness, anxiety, anger, dissatisfaction and sexual disorders often underlie dysfunctional relationships) (31).

Some teorical limitations of this study were the facts that is not blinded (it is not possible to blind a psychotherapy group), the absence of a placebo group versus Dapoxetine (in the presence of a drug with certain indication for the treatment of PE it didn't seems ethical a placebo group). The follow up is not extremely long but congruos with the aims of a prospective randomized study and the superior efficacy of a short therm therapy (30). It should be interesting in future studies to evaluate with a cross-over analysis the correlation between single arms. Another potential limitation of the study is the lack of an objective method for the evauation of IELT, as the stop watch techniques, but this is a method unfit in the clinical setting of our patients and in any case the authors give more importance of the subjective evaluation of the time as reported by Jannini et al. (11) "the presence of a stopwatch, even for short diagnostic purpose, is not frequently accepted".

Poor compliance remains a limit of this disorder as also showed in a recent study of Mondaini et al. (24) but it's also depend on the organization problems linked to the psychotherapy.

\section{Conclusions}

The PE is a complex sexual disorder with a multifactorial pathogenesis that needs to be taken into account for proper treatment. This is only possible by adopting a multidisciplinary approach, Indeed, psychotherapeutic treatment not only contributes to treating the disorder in those cases in which the psychological pathogenesis is more relevant, but also decreases anxiety, reducing relapses and helping patients deal with the disorder. Ultimately, an improvement of QoL is achieved in those patients. Our study highlights the importance in considering a combination of therapies as a correct way to treat PE, either due to a hypothetical psychological etiology, or due to frequent PErelated psychological consequences. Our results showed that psychotherapy may also improve the efficacy of pharmacotherapy (compliance with medical treatment).

Moreover, in our experience Group Psychotherapy seems to be suitable also for patients with this kind of sexual disorder (25). Finally, as claimed by Hunt and McHale (28) who stated that "for most men the most effective treatment for andrological disorders, depending on the cause of the problem, may be a combination of medical and psychological treatment", we would like to underline the importance of multidisci- 
plinarity $(32,33)$ : our data showed that group $C$, treated with the combination of pharmacotherapy and psychotherapy, was the one that improved the most in terms of results, as shown in Table 2. According to the results of our study, Group Psychotherapy appears to be effective in improving IELT, sexual satisfaction and anxiety both alone or in combination with Dapoxetine in treatment of PE. Considering the multi-pathogenic nature of $\mathrm{PE}$, combined treatment seems to be preferable to a single therapy, whether pharmacological or psychotherapeutic, even though the study does not show any statistically significant difference between treated groups.

\section{REFERENCES}

1. Althof SE, McMahon CG, Waldinger MD, et al. An update of the International Society of Sexual Medicine's guidelines for the diagnosis and treatment of premature ejaculation (PE). J Sex Med. 2014; 11:1392-422.

2. Laumann EO, Paik A, Rosen RC. The epidemiology of erectile dysfunction: Results from the National Health and Social Life Survey. Int J Impot Res 1999; 11(Suppl 1):S60-4.

3. Cooper K, Martyn-St James M, Kaltenthaler E, et al. Behavioral Therapies for Management of Premature Ejaculation: A Systematic Review. Sex Med. 2015; 3:174-88

4. Althof SE. Psychological approaches to the treatment of rapid ejaculation. JMHG. 2006; 3:180-186

5. Abdo CH, Afif-Abdo J, Otani F, Machado AC. Sexual satisfaction among patients with ED treated with counseling, sildenafil or both. J Sex Med. 2008; 5:1720-6.

6. Althof SE, Needle RB. Psychological and interpersonal dimensions of sexual function and dysfunction in women: An update. Arab J of Urol. 2013; 11:299-304.

7. Perelman MA. The treatment of premature ejaculation by time-limited, group sex therapy, Columbia University, 1980.

8. Zilbergeld B. Group treatment of sexual dysfunction in men without partners; J Sex Marital Ther. 1975; 1:204-214.

9. Di Maria F, Lo Verso G. La psicodinamica dei gruppi. Raffaello Cortina, Milano, 1995.

10. Symonds T, Perelman MA, Althof S, et al. Development and validation of a premature ejaculation diagnostic tool. Eur Urol. 2007; 52:565-73.

11. Jannini EA, Lenzi A. From diagnosis to treatment: the office management of premature ejaculation In: Jannini EA, McMahon CG, Waldinger MD Eds.: Premature Ejaculation. From etiology to diagnosis and treatment, Springer 2013, p.334.

12. Sanavio E, Bertolotti G, Michielin E, et al. CBA 2.0-Scale Primarie. OS: Florence, Italy 1986.

13. Spielberger CD, Gorsuch R, Lushene RE. Manual for the State Trait Anxiety Inventory. Consulting Psychologist Press; Palo Alto, Calif, US, 1970.

14.Aversa A, Rocchietti-March M, Caprio M, et al. Anxiety-induced failure in erectile response to intracorporeal prostaglandin-E1 in nonorganic male impotence: a new diagnostic approach. Int J Androl. 1996; 5:307-313.

15. Rocco A, Mori F, Baldelli R, et al. Effect of chronic bromocriptine treatment on psychological profile of patients with PRL-secreting pituitary adenomas. Psychoneuroendocrinology. 1993; 18:57-66.

16. Pratt JH. Principles of class treatment and their application to var- ious chronic diseases. In Hospital Social Service Quarterly. 1922; 6:401-411.

17. Sabin JE. Joseph Hersey Pratt's cost-effective class method and its contemporary application: some problems in biopsychosocial innovation. Psychiatry. 1990; 53:169-184

18. Marinelli S. Funzioni dell'omogeneità nel gruppo. In: Corbella S, Girelli R, Marinelli S. Gruppi omogenei. Borla, Roma, 2004.

19. Semans JH. Premature ejaculation: a new approach. South Med J. 1956; 49:353-358.

20. Masters WH, E Johnson VE. Human Sexual Inadequacy. Boston: Little, Brown \& Co. 1970.

21. Kaplan HS. The New Sex Therapy. New York: Brunner/Mazel. 1974.

22. Limoncin E, Tomassetti M, Gravina GL, et al. Premature Ejaculation results in female sexual distress: standardization and validation of a new diagnostic tool for sexual distress. J Urol. 2013; 189:1830-5.

23. Pavone C, Scalici Gesolfo C, Abbadessa D, et al. Compliance to therapy with Dapoxetine in patients affected by Premature Ejaculation. Urologia. 2013; 80:53-63.

24. Mondaini N, Fusco F, Cai T, et al. Dapoxetine treatment in patients with lifelong premature ejaculation: the reasons of a "Waterloo". Urology. 2013; 82:620-4.

25. Martyn-St James M, Cooper K, et al. Topical anaesthetics for premature ejaculation: a systematic review and meta-analysis. Sex Health. 2016; 13:114-23.

26. Rosen RC, Leiblum SR: Treatment of male erectile disorders: Current options and dilemmas. Sexual and Marital Ther. 1993; 8:5-8.

27. Rosen RC, Leiblum SR. Treatment of sexual disorders in the 1990s: An integrated approach. J of Consulting and Clinical Psychology. 1995, 63:877-890.

28. Hunt N, McHale S. What is the importance of psychosocial issues, counseling and psychotherapy in Andrology. In: The American Society of Andrology: Handbook of Andrology - II Ed., Allen Press. 2013.

29. Budman SH, Simeone PG, Reilly R, Demby A. Progress in shortterm and time-limited group psychotherapy: evidence and implications. In A. Fuhrinam e GM. Burlingame (Eds), Handbook of Group Psycotherapy. An empirical and clinical synthesis. New York: Wiley. 1994.

30. Sledge WH, Moras K, Hartley D, Levine M. Effect of time-limited psychotherapy on patients drop-out rates. American Journal of Psychiatry. 1990; 147:1341-1347.

31. Graziottin A, Althof S. What does mean to the man, the woman and the couple? J. Sex Med. 2011; 8(suppl. 4):304-309.

32. Rowland D, Cooper S. Practical tips for sexual counseling and psychotherapy in premature ejaculation, J Sex Med. 2011; 8(Suppl 4):342-52.

33. Perelman MA. A new combination treatment for Premature Ejaculation: a sex therapist's perspective. J Sex Med. 2006; 3:1004-12.

\section{Correspondence}

Carlo Pavone, MD (Corresponding Author)

carlo.pavone@unipa.it

Daniela Abbadessa, MD - danielaabbadessa@hotmail.com

Giuseppa Gambino, MD - gambino.giusi@alice.it

Giovanna Scaduto, MD - giovanna.scaduto@libero.it

Marco Vella, MD - marco.vella@libero.it

Via del Vespro 129, 90100, Palermo, Italy 